\title{
Identifying Green Services using GSLA Model for Achieving Sustainability in Industries
}

\author{
Iqbal Ahmed \\ Graduate School of Science and \\ Engineering, Saga University, Japan
}

\author{
Hiroshi Okumura \\ Graduate School of Science and \\ Engineering, Saga University, Japan
}

\author{
Kohei Arai \\ Graduate School of Science and \\ Engineering, Saga University, Japan
}

\begin{abstract}
Green SLA (GSLA) is a formal agreement between service providers/vendors and users/customers incorporating all the traditional/basic commitments (Basic SLAs) as well as incorporating Ecological, Economical, and Ethical (3Es) aspects of sustainability. Recently, most of the IT (Information Technology) and ICT (Information and Communication Technology) industries are practicing sustainability under green computing domain through designing green services at their scope. However, most of these services only focused on power consumption, energy efficiency, and carbon emission. Moreover, the sustainability can not achieve without considering 3Es simultaneously. The recent development of sustainable GSLA are assisting to identify the missing green services under 3Es. This research attempts to design all missing green services for sustainability by using global informational model of Green SLA. All these newly identified green IT services could reside with other existing services in the industry. Additionally, the design and evaluation technique of these new green services could be used as a guideline for the ICT engineers and as well as other industries too. Moreover, the evaluation and monitoring of new green services are justified using general questionnaires design and analytical tools among the 20 startup ICT industries in Bangladesh and Japan. The proposed idea of designing new green services and their justification methods would be helpful for the ICT engineer to practice sustainability in their competitive businesses.
\end{abstract}

Keywords_GSLA; Green Services; GaaS; Sustainability; Informational model

\section{INTRODUCTION}

Currently, cloud and grid computing and many data centers act as most promising service providers. These computing and communication industry provides different services in compare to traditional computing with some scalability benefits. At the same time, cloud services are offered at various levels: Infrastructure, Platform and Software as a Service [1, 2]. At each level, they maintain a SLA and or GSLA with their parties [2]. Therefore, this shows the growth rate of GSLA in recent time as well as the need of introducing green services for sustainability [3]. Presently, the revolution of ICT and IT in average daily life has also resulted in the increase of Green House Gas (GHG), due to a continual increase in "carbon footprint" [4]. If ICT has a negative impact on the environment, it can use for greening the other human activities (logistic, city, industry, etc.) in the society [4, 5]. Indeed, the dimensions of Green Informatics contributions are: the reduction of energy consumption, the rise of environmental awareness, the effective communication of environmental issues and the environmental monitoring and surveillance systems, as a means to protect and restore natural ecosystems potential [6]. At the same time, many ICT companies or service providers need to think about their business scope in the light of green and sustainable perspective $[7,8]$. The GSLA research assists to understand the sustainability achievement from customers/users and service providers side for upcoming sustainable society [3, 9]. According to Gartner (2015), green IT services refer to the development of green IT to enable organizations in creation, management, and optimization of or access to information in the business process [10]. However, develop a standard green IT services under sustainability domain is still a challenging task for the ICT engineer. Now it is timely to conduct another layer of Green IT as a services (GaaS)with their existing service infrastructure considering 3Es of sustainability (Fig.1). According to figure 1, the interaction of 3Es of sustainability makes it difficult to design new green services on top of it. All these new green indicators of GSLA under ecology, economy and ethics are already identified by the previous study [3,9].

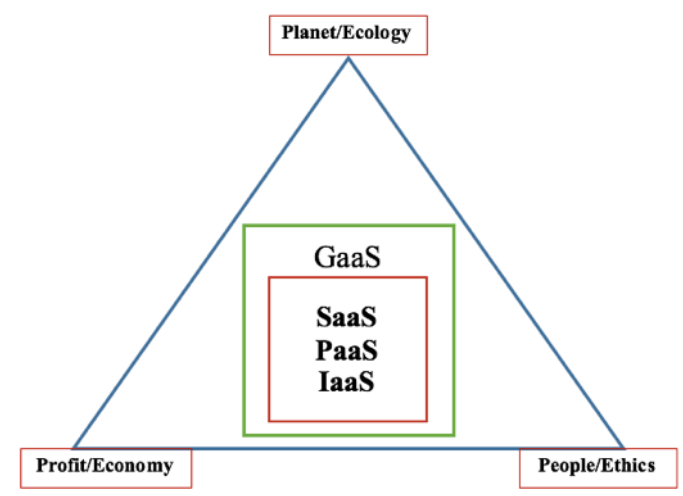

Fig. 1. Overview of Green IT as a Service (GaaS) under sustainability

This research identified new green services from a general model of sustainable GSLA [9] and GSLA is the only way to understand the importance of sustainable development in both sides (customers and providers). These identified seven new green services from the GSLA model [9] are shown in next Table 1 . The table also depicts the cascading relationships (direct, indirect important and indirect small effects) between other parameters under 3Es of sustainable GSLA model [9]. All these newly identified green services are modeled using UML notation under GSLA hood, thereby interacting 3Es of sustainability. Moreover, this research attempts to justify “Total Recycling Services” using general questionnaires and their feedback analysis. The analytical results suggest that, new ICT industries are considering the green services for 
achieving sustainability though there are still some interaction gaps with the proposed designed green services.

TABLE I. RELATIONSHips BetweEn All SERVICES DEFINED FROM the GSLA INFORMATIONAL MODEL[9]

\begin{tabular}{|c|c|c|c|}
\hline \multirow[b]{2}{*}{$\begin{array}{l}\text { Identified } \\
\text { new green } \\
\text { services }\end{array}$} & \multicolumn{3}{|c|}{ Relationships with other indicators under 3Es } \\
\hline & Direct & $\begin{array}{l}\text { Indirect } \\
\text { Important Effects }\end{array}$ & $\begin{array}{l}\text { Indirect } \\
\text { Small } \\
\text { Effects }\end{array}$ \\
\hline $\begin{array}{l}\text { Total } \\
\text { Recycling }\end{array}$ & $\begin{array}{l}\text { ICT Product Life Cycle; } \\
\text { eWastage; } \\
\text { Earth Pollution; } \\
\text { Energy Consumption; } \\
\text { GHG Emission; } \\
\text { Energy Cost; } \\
\text { Dismantling ICT Product. }\end{array}$ & $\begin{array}{l}\text { ICT Radio Wave; } \\
\text { ICT Toxic Material } \\
\text { Usage; } \\
\text { ICT Product Life } \\
\text { Cost. }\end{array}$ & $\begin{array}{l}\text { Comfort } \\
\text { Pollution }\end{array}$ \\
\hline $\begin{array}{l}\text { Obsolescence } \\
\text { Indication }\end{array}$ & $\begin{array}{l}\text { ICT Product Life Cycle; } \\
\text { ICT Performance; } \\
\text { ICT Product Life Cost. }\end{array}$ & $\begin{array}{l}\text { Pollution Level; } \\
\text { Energy } \\
\text { Consumption; } \\
\text { GHG Emission }\end{array}$ & Ethics Pillar \\
\hline GHG Emission & $\begin{array}{l}\text { Total Recycling; } \\
\text { Air Pollution; } \\
\text { Non-renewable Energy; } \\
\text { Carbon Taxation; } \\
\text { Dismantling ICT Product; } \\
\text { Energy Consumption. }\end{array}$ & $\begin{array}{l}\text { Obsolescence } \\
\text { Indication; } \\
\text { ICT Toxic Material } \\
\text { Usage }\end{array}$ & $\begin{array}{l}\text { Comfort } \\
\text { Pollution }\end{array}$ \\
\hline $\begin{array}{l}\text { Energy } \\
\text { Consumption }\end{array}$ & $\begin{array}{l}\text { Total Recycling; } \\
\text { ICT Product Life Cycle; } \\
\text { ICT Product Life Cost; } \\
\text { Energy Cost; } \\
\text { Carbon Taxation; } \\
\text { GHG Emission; } \\
\text { Renewable Energy; } \\
\text { ICT Radio Wave. }\end{array}$ & $\begin{array}{l}\text { Obsolescence } \\
\text { Indication; } \\
\text { Cooling Cost }\end{array}$ & $\begin{array}{l}\text { Civil } \\
\text { Engineering } \\
\text { Cost }\end{array}$ \\
\hline Pollution Level & $\begin{array}{l}\text { ICT Product Life Cycle; } \\
\text { Total Recycling; } \\
\text { ICT Radio Wave; } \\
\text { GHG Emission; } \\
\text { Energy Type. }\end{array}$ & $\begin{array}{l}\text { ICT Toxic Material; } \\
\text { Obsolescence } \\
\text { Indication; } \\
\text { Energy } \\
\text { Consumption. } \\
\end{array}$ & Ethics Pillar \\
\hline $\begin{array}{l}\text { ICT Product } \\
\text { Life Cycle }\end{array}$ & $\begin{array}{l}\text { Energy Consumption; } \\
\text { ICT Product Life Cost; } \\
\text { Pollution Level; } \\
\text { Obsolescence Indication; } \\
\text { Total Recycling; } \\
\text { Energy Cost. }\end{array}$ & GHG Emission & \\
\hline Energy Cost & $\begin{array}{l}\text { ICT Product Life; } \\
\text { ICT Product Cost; } \\
\text { Carbon Taxation; } \\
\text { Energy Consumption; }\end{array}$ & $\begin{array}{l}\text { Cooling Cost; } \\
\text { Civil Engineering } \\
\text { Cost; }\end{array}$ & $\begin{array}{l}\text { Total } \\
\text { Recycling; }\end{array}$ \\
\hline
\end{tabular}

The rest of the work is organized as follows- the next section elaborate the importance and designing of all newly identified green services under sustainability hoods. The evaluation and discussion section discovers the justification of proposed designed model of Total Recycling Services from various ICT startup industries from Bangladesh and Japan. In addition, this section also highlights the evaluation techniques of these non-technical green services. Finally, the conclusion gives a brief discussion about few challenges and plan of this green service designing and implementation in the industry.

\section{DESIGNING GREEN SERVICES FROM GSLA INFORMATIONAL MODEL}

The sustainable GSLA definition [3] and global informational model [9] helps to identify the complexity of managing all GSLA parameters by taking some of the important services from sustainability pillars and existing green computing practice. All these central entities have direct and indirect relationships for evaluating and assessing all existing performance parameters of the proposed global GSLA model [9]. Additionally, choosing central entities might also help the ICT designer to view and design new services for the users. Moreover, these new services actually cover all the dependencies and respect all other existing and new indicators under three pillars of sustainability (Table I) and traditional green computing practice in IT industry. The rest of the work organizes all these services showing its direct relationships and indirect important and small effects with other entities using a UML notation. Therefore, this research identifies following central entities as new services in the future sustainable industry, - Total Recycling, Obsolescence Indication, GHG Emission, Energy Consumption, Pollution level, ICT Product Life Cycle and Energy Cost. All these new services need to consider for achieving sustainability as these are the missing services proved from previous studies [3, 9].

\section{A. Total Recycling Services}

Total Recycling has interrelationships with other existing and new indicators in the model (Fig.2). While recycling an item or ICT product, it could emit GHG directly into the atmosphere. Moreover, it has direct impact and relation with Earth Pollution entities (Air, water, and soil). For example, Cathode Ray Tube (CRT) used in computer monitors could emit lead, barium, and other heavy metals into the ground water and release toxic phosphor into the air [11]. Again, computer and networking wires could also recycle for extracting copper using open burning and stripping method, which creates hydrocarbon ashes released into the air, water and soil in the environment [11]. The Air Pollution entity is directly related with GHG Emission in proposed model. Recycling has a direct relationship with the eWastage entity. Recycling helps to the reduce global magnitude of e-waste as metals, plastics, glass and other materials could be recovered from ICT product through recycling procedure. eWastage entity has direct impact on GHG Emission and Energy Consumption entity in this model. Moreover, to recycle a product or equipment, it needs to consume energy or power and cost of energy need to consider. Total Recycling has direct relations to calculate existing Energy Consumption, Energy Cost indicators. ICT Toxic Material Usage makes recycling indicator more complex. Most of the toxic materials used in ICT industry have important indirect effects to the Comfort Pollution entity because the dumping or recycling procedure might irritate people's comfort through noise or visual pollution and also responsible for health hazards. For example, in fluorescent tubes, flat screen monitors, etc. mercury and its compound is used. This toxic material affects human health including sensory impairment, dermatitis, memory-loss, and muscle weakness [11]. Sulfur and lead are also commonly used in lead-acid batteries, might responsible for acute health problems such as liver, kidney, heart damage, behavioral disturbances, attention deficits and lower IQ [11]. Besides all these comfort level pollution, toxic material usages also have a direct relation with other earth pollution entity. Earth pollution of mercury and its substance affects plants, trees by reducing soil's fertility rate and thus slower their growth and development [11]. Also, when Sulfur released, it could create Sulphur dioxide, which is responsible for acid rain [10]. ICT Radio Wave could measure and monitor through standard value of EMF (Electromagnetic Frequency) or SAR (Specific Absorption Rate) value for some specific domain such as network or the internet etc. SAR is a measure of the rate at 
which energy is absorbed by the human body when exposed to radio frequency; SAR also defines as power absorbed per

mass tissue and has units of Watts per kilogram (W/Kg) [12].

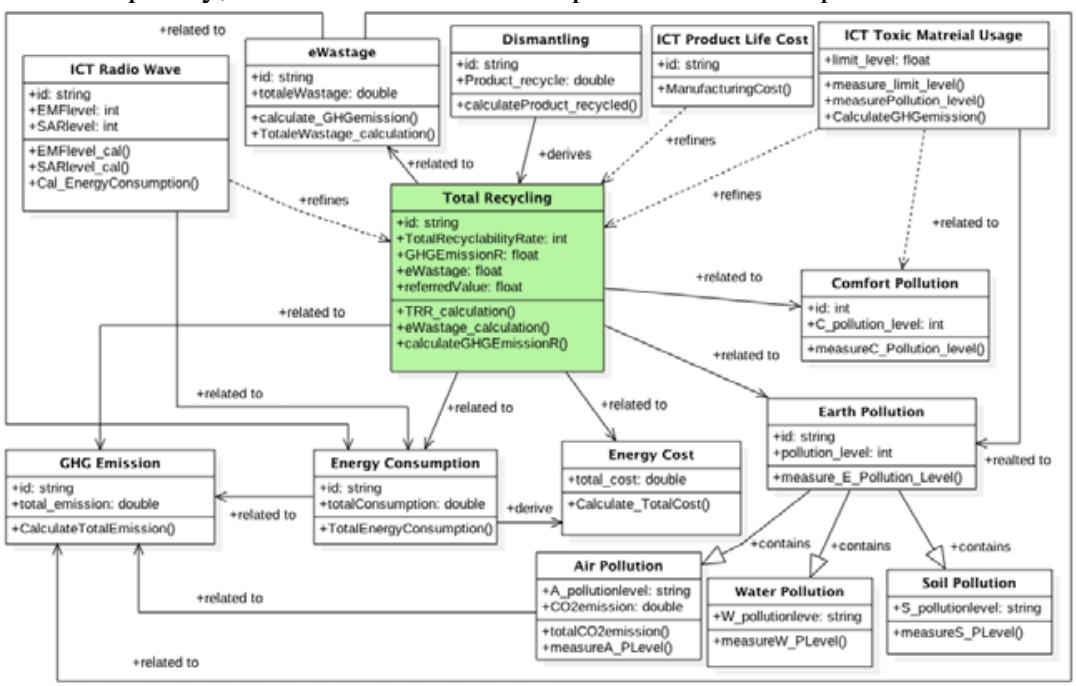

Fig. 2. Total Recycling Service

Also, ICT Radio Wave have direct relation with Energy Consumption, as to reduce the power of wave, it also requires installing more antenna; which consumes more energy and thus more money for that consumed energy and at the same time, more antenna increases the problem of equipment recycling. Total Recycling service has impact on Economic Pillar of sustainability as the more product would be recycled, the more money could gain. However, the cost of energy and other necessary costs to recycle ICT product also need to consider here. The Dismantling entity from ICT Product Life Cycle has direct relations with recycle, reuse or refurbish entity [3]. Additionally, Manufacturing entity of ICT product life refines total recycling entity as recycling helps to avoid extracting new earth resources as well as minimizes production cost to some extents. Thus, it has relation with economic indicator- ICT Product Life Cost. The main challenges to define this new Total Recycling services are to gather all necessary information and monitoring their effect. Most of non-technical parameters under sustainability pillar in this service need some laws and directives to derive exact information for the users. There are some standards available for recycling services in the USA (Responsible Recycling (R2) Practices, $e$-Steward) and also some directives such as WEEE or D3E from the European Union.

\section{B. Obsolescence Indication Service}

Obsolescence Indication could be another green service under the ecological pillar of sustainability [3, 9]. Minimum optimum obsolescence could be calculated using some mathematical model design for an ICT product and for the raw materials to produce that product $[13,14,15,16]$. Additionally, Obsolescence Management could also be used to find out the optimum indication for a product to be obsolete $[15,16]$. However, obsolescence is relative information estimated from other useful existing criteria. It could calculate from cost of energy, carbon/GHG emission, ICT product life cycle assessment, and or pollution level. There is an interesting relation between obsolescence and people. Therefore,
Obsolescence Indication entity has indirect relationship with Ethics Pillar entity of GSLA model [9]. There is an interesting relationship between existing User Satisfaction indicator with this entity. For example, people often change their mobile phone frequently because it might become old fashioned to use it. Moreover, to find out the optimum obsolescence of ICT equipment, the performance of that equipment should need to monitor and evaluate using classical/basic SLA parameters (availability, connectivity, bandwidth capacity, memory, uptime, and etc. for a switch). That's why, obsolescence indication entity need to incorporate the ICT equipment basic performance metric. The next Fig.3 shows the graphical notation of obsolescence indication service. There is still no available standard to define obsolescence indication. Obsolescence management of an ICT product could define according to design some regulatory lever, education/training for user behaviors and recycling practice in the society.

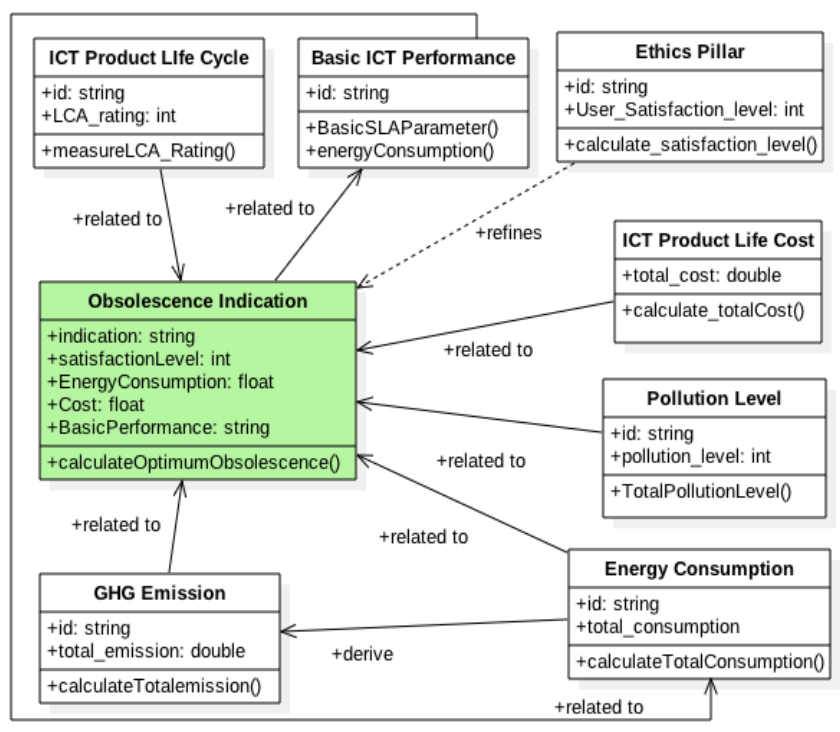

Fig. 3. Obsolescence Indication Service 


\section{GHG Emission Service:}

Currently, Green House Gas (GHG) emission parameter exists in some previously defined GSLA for ICT industry[8]. This global service has a direct impact on the environment under sustainability lens. Fig.4 gives the idea of interrelationships and dependency of GHG Emission service. Air Pollution entity from ecological pillar has direct relationship with GHG Emission in the proposed model as the more air is polluted; the more carbon is emitted into the atmosphere. Additionally, the air is polluted because of carbon emission and this emission related with energy consumption issues.

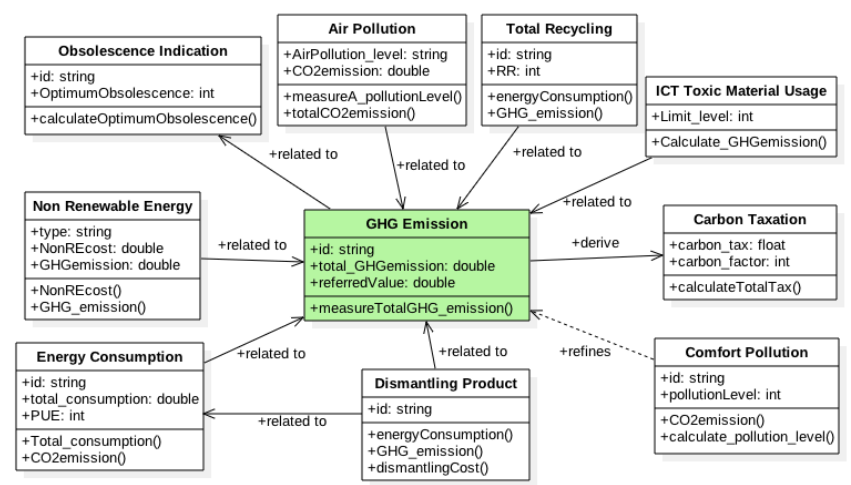

Fig. 4. GHG Emission Service

However, there are two types of energy currently used in most industries,- renewable energy and non-renewable energy. Non-renewable energy such as coal, oil, and natural gas is more responsible for producing GHG emission whereas renewable energy (Solar, Wind, Tidal, Nuclear, etc.) has negligible effects on GHG emission. Therefore, the GHG Emission entity has direct relationship with non-renewable energy type in the proposed model. The Comfort Pollution entity has an indirect small effect on GHG emission. The ICT product which is responsible for creating noise, light or visual pollution under comfort pollution level, might also emit carbon into the atmosphere. Moreover, GHG emission entity has direct relations with an economic entity in GSLA- Carbon taxation. Carbon Taxation usually derived after measuring total carbon emission and carbon factor in any facility/industry. Though carbon factor is varying according to different country's government rules and regulation, it plays an important role to calculate total carbon tax.

\section{Energy Consumption Service:}

Fig. 5 is demonstrating energy consumption service under green computing domain. This service has close relationships and dependencies to derive some existing indicators. For example, Power Usage Effectiveness (PUE) derived as the ratio between total energy consumption and IT energy consumption [17] and to completely find out total energy consumption; the Energy Consumption service is relating to all other entities in the model. Moreover, ITEE, ITEU [18] and Green Energy Coefficient (GEC) [19] indicators help to find Data center Performance Per Energy (DPPE) [17, 19] in existing green SLAs. GEC calculated from renewable energy source entity in the proposed model. Additionally, ICT Product Life is an important entity for GSLA on energy consumption issues in the model. The manufacturing, transportation, usage and dismantling entity an ICT product requires energy in each stage. There are some EnergyWise standard ICT products from CISCO, which already used in many industries. The network engineer could easily monitor the real-time energy consumption of devices compatible with this EnergyWise [20] standard. Again, either for recycling, reusing or refurbishing procedure of an ICT product or equipment also needs energy. Therefore, ICT Product Life Cycle and Total Recycling services have direct and continuous dependencies for calculating energy consumption services. The more energy consumed; the more carbon emitted. The real-time energy consumption and carbon emission correlation observed during PERCCOM air quality project [20]. Thus, GHG Emission also has direct relationship with Energy Consumption entity. ICT Radio Wave has an important indirect effect because to reduce the power of radio, more antenna and other equipment are requires which also consume more energy.

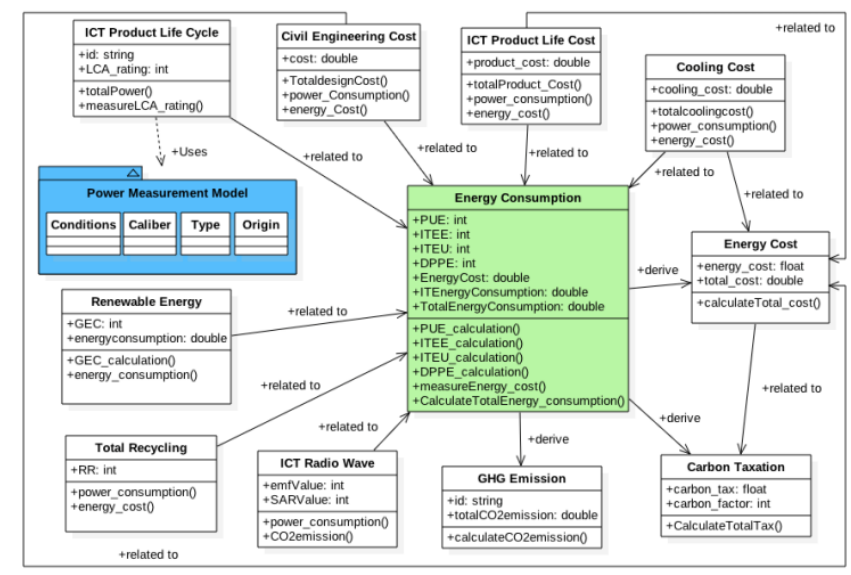

Fig. 5. Energy Consumption Service

Moreover, Energy Cost and Carbon Taxation, both economic entities have a direct impact on energy consumption in IT industry. Civil Engineering Cost, ICT Product Life Cost, and Cooling Cost have important indirect effects on this entity. In each stage of building or infrastructure design, it requires energy/power and also for installing ICT product in any facility needs energy too. In addition, the cooling techniques demand more energy than their ICT equipment in some ICT industry. All these economic entities depend on the calculation of energy consumption first and then their measurement according to different countries energy/power regulations. In addition, the power measurement model [21] could also be helpful to refine energy consumption service. The general relation between energy and power consumption of an ICT device could be derived as [21],

$$
\text { energyconsumption }=\int_{\text {time }} \text { powerconsumption }
$$

The main purpose of a power measurement model is to introduce a reference value for the power consumption of an ICT device during its life time. The model has relations with other entities, such as power measurement conditions, caliber, power/current type, and origin of power [21]. Here, in the 
proposed energy consumption service, the integration of the power measurement model is not shown directly for simplicity. However, the model could be important for evaluating and assessing the total energy consumption of an ICT power enabled device.

\section{E. Pollution Level Service:}

Pollution level service is important from ecological aspects of sustainability. ICT Product Life Cycle, ICT Toxic Material Usage, Total Recycling, and GHG Emission have direct relationship with pollution level service whereas ICT Radio Wave and Obsolescence Indication entities have indirect important effects on both earth and comfort pollution. There is an interesting relationship between Comfort Pollution entities with ethics pillar in the GSLA model [9] as ethical pollution is mostly concerned with people's comfort in their daily life. Noise Pollution, Light Pollution and Visual Pollution are the most three important comfort level pollution entities. Noise Pollution should need to calculate the standard level of noise in decibels (according to E-OSHA standard); Light Pollution might create Computer Vision Syndrome (CVS) [22, 23] on human health and this indicator should need some guideline and modeling to control CVS. Visual Pollution could monitor and control according to PAQ (Perception of Affective Quality) rating[24]. The earth pollution level entity is consists of three other entities, - Air, Water, and Soil Pollution and Air Pollution is directly responsible for GHG Emission in the atmosphere (Fig.2). Air, water, and soil pollution have direct relations with recycling, ICT toxic material usages and ICT radio wave entity. Pollution level central entity and its relationships are shown next Fig.6. Additionally, existing Carbon Usage Effectiveness (CUE) indicator is computed here as total carbon emission equivalent from the total energy consumption for any facility [19]. Therefore, this entity has relation to derive $C U E$ using the formula, $C U E=C E F \times P U E$; whereas $C E F$ is the carbon emission factor, which could vary according to different countries government rules and regulation [20, 25].

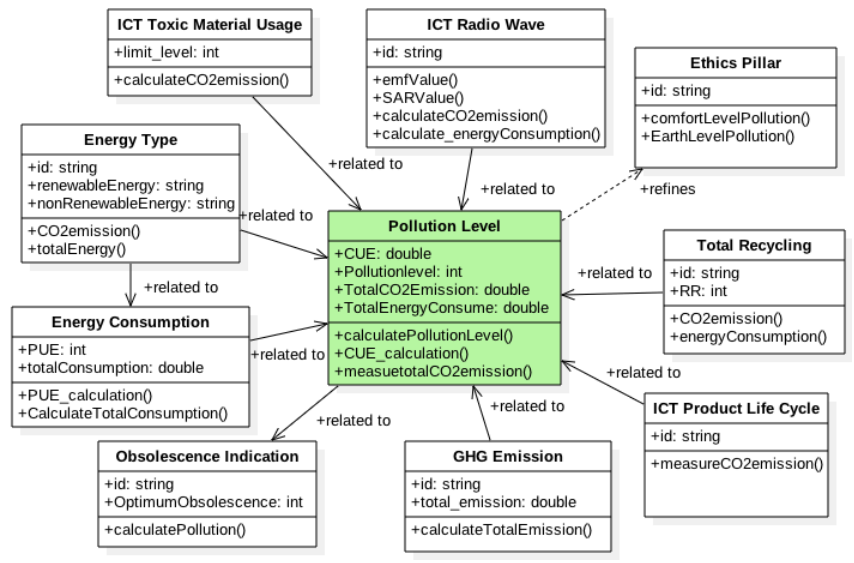

Fig. 6. Pollution Level Service

\section{F. ICT Product Life Cycle Service:}

The whole life cycle of an ICT product consists of following entities, - manufacturing, transportation, usage and dismantling entities [3]. All these entities should directly connect to GSLA entity to respect global analysis of proposed model[3, 9]. The total GHG emission, total energy consumption and total costing of energy could not be estimated without considering all these product life cycles entities [26]. Therefore, GHG Emission, Energy Consumption, Pollution Level, Total Recycling entities of ecological pillar and Energy Cost of the economic pillar has direct relations with ICT Product Life Cycle service. Moreover, ICT Product Life Cost, which usually consider the production, usage level costs, and initial setup costing; have also an important indirect effect on life cycle's entity. Fig.7 depicts this central service and shows its corresponding relationship with other entities.

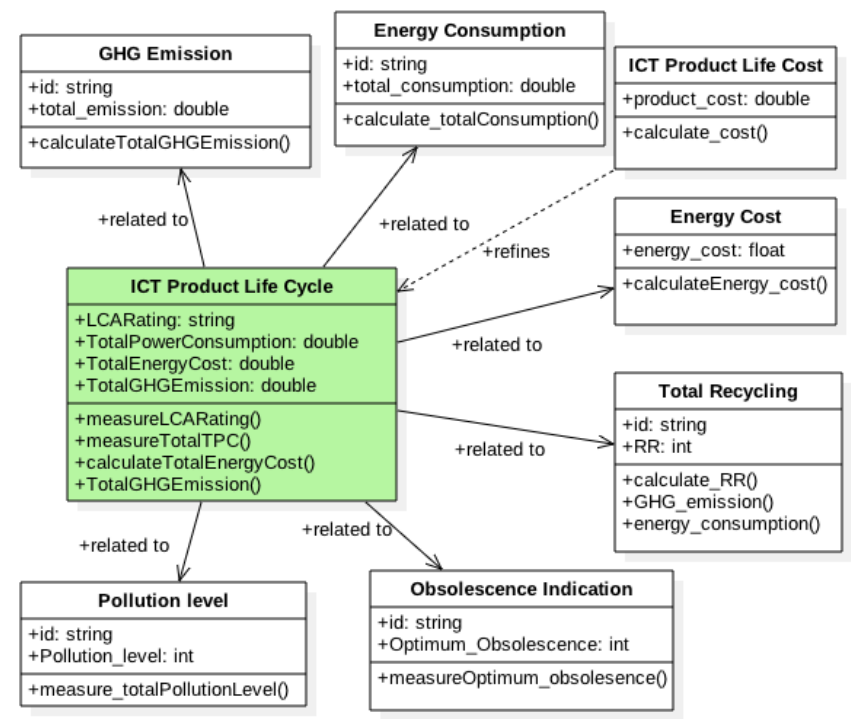

Fig. 7. ICT Product Life Cycle Service

Again, there is also an interesting relation between the dismantling entity of ICT product life cycle and ICT Product Life Cost as dismantling could be refined either with recycling, reuse or refurbish entity and the production cost will be reduced. For example, gold could retrieve after reusing old ICT equipment, which helps to reduce the production cost of new ICT product and also there might be no need to explore more earth resources. Therefore, Dismantling entity in ICT product life cycle has a direct relationship with ICT Product Life Cost. The power consumption model [21] could be used to refine ICT Product Life Cycle for evaluating total energy consumption in product's whole life time, which already depicts in Fig.5.

\section{G. Energy Cost Service:}

Fig.8 demonstrates the analysis of Energy Cost service. This service has direct relations with ICT Product Life Cycle, Energy Consumption, Carbon Taxation and Energy Type. There are two types of energy is considered in the model, renewable, and non-renewable energy. The costing of energy depends on the types of energy sources used in the ICT facility. However, different types of energy cost generally depend on different countries government rules and regulations and their economic conditions. Again, the carbon tax calculated after retrieving energy cost according to government rules and regulation. At each stage of the life cycle for an ICT product, it demands energy and thus costing of these energy need to consider. Recycling procedure also 
requires energy and money but also money could gain after reusing a recycled material for further use. Therefore, Total Recycling service also has a direct relation with energy cost entity in the model.

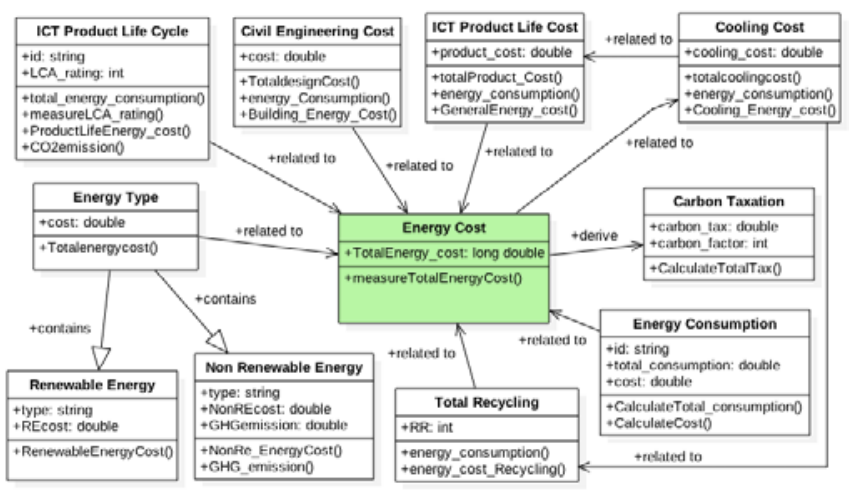

Fig. 8. Energy Cost Service

Moreover, ICT Product Life Cost, Cooling Cost, and Civil Engineering Cost has important indirect effects on energy costing issues. In future, the cost of depollution should need to consider here. Cooling Cost entity has important and interesting relations with recycling and ICT product cost issues. Currently, a huge amount of money spent on data center cooling facility, which actually motivates from the work on temperature management [27]. In some case, the idea to reduce the cooling cost is to increase the threshold of temperature acceptable for a server in the data center. However, temperature threshold has negative impacts on server reliability and performance [27]. The consequence of this scenario is that, it needs to change the server and other equipment prematurely in any data center facility. Therefore, the cooling cost entity might have negative effects on ICT product cost entity of economic pillar as it needs more money to buy and install a new server. At the same time, prematurely damaged servers and other equipment could recycled for further use. Thus, cooling cost entity has direct relationships with the recycling service under the ecological pillar of sustainability [3, 9]. Additionally, the two types of cooling facility also need to consider for evaluating energy cost service in the model. For example, in the data center, natural cooling facility might more cost-effective and environmentfriendly than not a natural cooling facility.

The above figures (Fig.2 to Fig.8) depict the complexity of managing all the performance indicators to define new green services for achieving sustainability in the industries. All these designed services have different levels of relationships and interactions with other entities belonging to three sustainability pillars (Table 1 ). The next section discovers the real fact of evaluating new green services under sustainable development. This research aims to consider only one green service "Total Recycling” in this regard due to simplicity.

\section{VALIDATION AND IMPLEMENTION OF GREEN SERVICES}

It is clearly evident, all newly identified services have a different level of interrelationships among them. It is important to mention that, all the relationships regarding newly identified services (Table 1) are important to respect sustainable achievement.

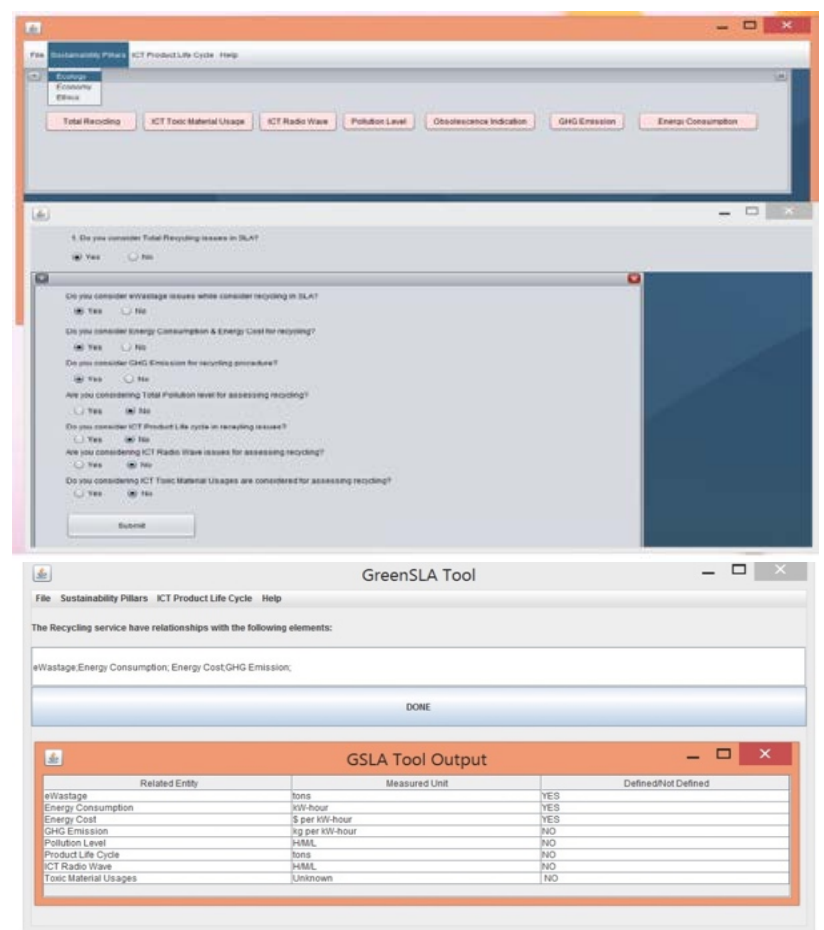

Fig. 9. Questionnaires generation under GSLA environment for recycling services

The ICT engineer should analyze their future green services by generating some questionnaires and then it's possible to evaluate their designed green services from the customer side. This is a small step to the way of justification of proposed designed services. The questionnaire is generated using Java (Eclipse Tool), following the UML model of Total Recycling Service (Fig.2) under sustainable GSLA environment. The generation of automated questionnaires represents in Fig.9. These questionnaires sent to 20 different ICT companies and as well as other companies in Bangladesh and Japan, who respect recyclability and sustainability in their business scope. Most of these industries are varied in sizes, Large, Medium, Small; and their response to the questionnaires were completely unbiased. Among the 20 industries, 15 ICT based industries delivered their answers for further analysis. The feedback of these industries is then analyzed using SAS analytical tool (JMP 12.2.0) and represented in next fig. 10-11.

The analysis revealed, most of this ICT-based industries taking consideration of recycling services while designing, developing, implementing or providing services/product to their customers. Fig.10 shows the feedback analysis of 15 industries and among them $66 \%$ medium (red color) and large sized industries respect recycling services under sustainability. The small sized (green color) industries are usually using the slogan of sustainability but they are far behind of considering the proposed green services. In contrary, most of the large size industries (blue color) are practicing recyclability though they are not pretending to be a sustainable industry due to the lack of knowledge to design new green services in their scope. 


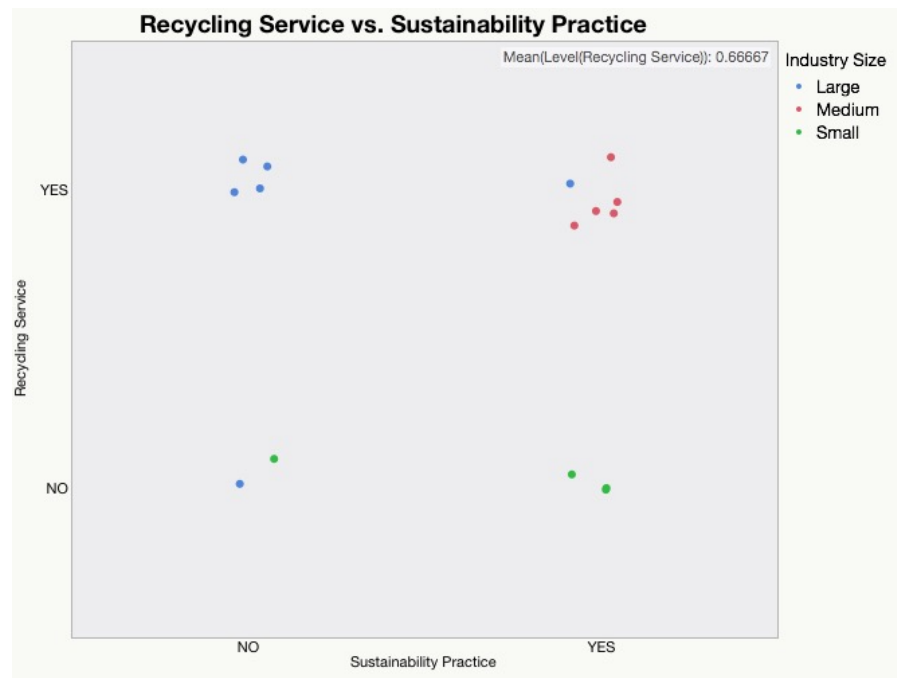

Fig. 10. Analysis of recycling services in different sized industries

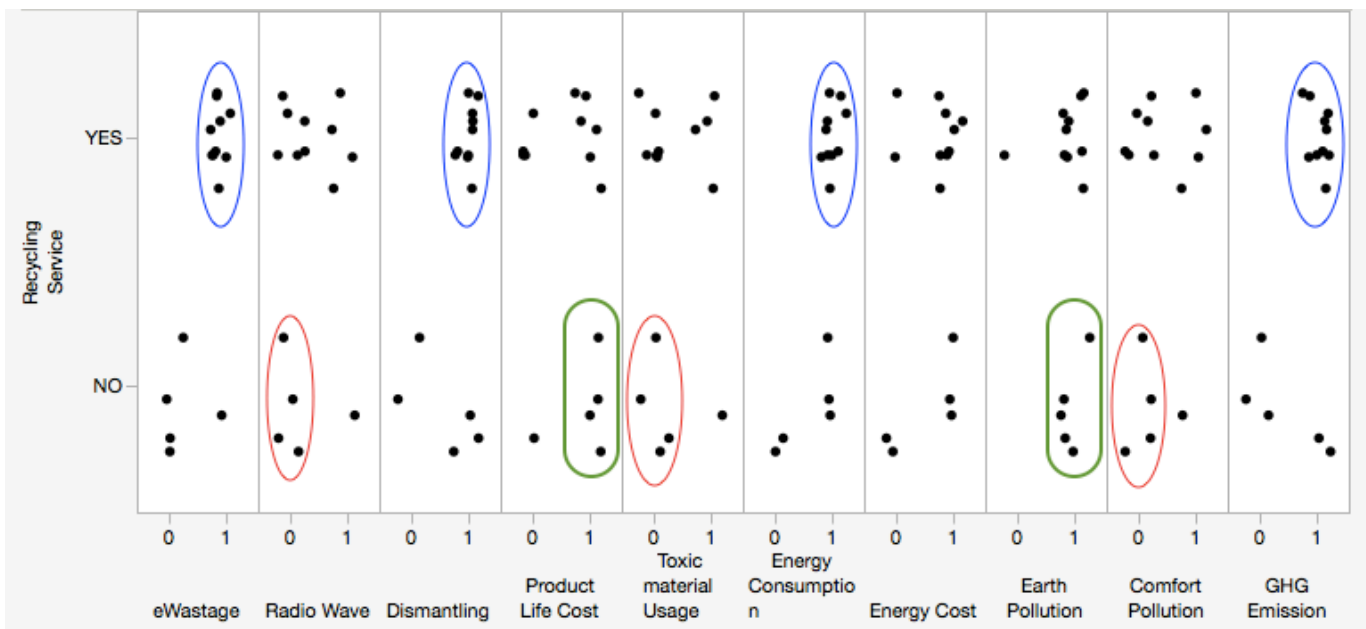

Fig. 11. Analysis of all entities of recycling services

However, these industries are unware of designing their recycling services with the proposed designed model (Fig.2). It is evident from the fig. 11 that, these companies are just consider the interaction of eWastage, energy consumption, energy cost, dismantling and GHG entities in their scope while ignoring Radio wave information, Toxic material, Comfort pollution entities.

It is noticeable that, very few industries (only 01 company) are justifying all entities and their different levels of interactions (Table 1) in compare to the proposed designed Total Recycling Services (Fig.2). The interesting fact is that, most of these industries concentrate on earth pollution and product life costing while not considering recycling services in their business scope. It shows the importance and awareness of practicing sustainability in businesses to some extent.

\section{CONCLUSION}

This research proposed new layer of green IT services on top of already existing services for the ICT industries to achieve sustainability. The identification and designation of all seven new green services (Fig.2 to Fig.8) derived from sustainable GSLA model. Therefore, these seven green services could be satisfied from both parties (users/customers and providers) of the businesses. The justification of recycling services (Fig.9 to Fig.11) could be used as a guideline for the ICT engineer or other industries to develop future green services in their scope. However, this research still has some challenges to face as the informational model of sustainable GSLA; green service infrastructure are needed to be standardized by proper authority, rules or directives. The standardization of green indicators and green services is one of the main issues as mentioned by ITU-T report (2012). Also, further research is necessary on monitoring and evaluating green services for a viable Green IT framework design. Most of the interactions and different level relationships in the proposed designed services are non-technical parameters. Moreover, some entities have interaction with human behavior in their evaluation and validation. Thus, it might be the most challenging task of monitoring those newly designed services in future. The next steps of this research is to justify all green srvices with more feedbacks and develop a viable Green IT as a Service (GaaS) infrastucture under sustainbility hoods for the industires. 


\section{ACKNOWLEDGMENT}

The authors would like to show their gratitude and thanks to PERCCOM program (European Union) for giving the idea of GSLA research.

\section{REFERENCES}

[1] SLA@SOI, Source: http://sla-at-soi.eu/, retrieved on April 2015.

[2] R. Buyya, J. Broberg, and A. Goscinsk, "Cloud Computing: Principles and Paradigm,” A John Wiley \& Sons, Inc. Publication, ISBN: 978-0470-88799-8, February 2011.

[3] I. Ahmed, H. Okumura, and K. Arai, "Analysis on existing Basic SLAs and green SLAs to define new sustainable Green SLA", International Journal of Advanced Computer Science and Applications, Vol.6, No. 12, December 2015, pp. 100-108.

[4] J. Mankoff, R. Kravets, and E. Blevis, "Some Computer Science Issues in Creating a Sustainable World,” Computer, Vol. 41, No. 8, 2008.

[5] SMART 2020 Report, "Enabling the low carbon economy in the information age,” The Climate Group, GeSI, 2008.

[6] Z. S. Andreopoulou, "Green Informatics: ICT for Green and Sustainability," Journal of Agriculture Informatics (EIFTA), Vol. 3, No. 2, 2012.

[7] K. Van Wensen, W. Broer, J. Klein, and J. Knopf, "The State of Play in Sustainability reporting in the European Union”, Executive Summery, The European Union's Programme for Employment \& Social Solidarity, CREM/adelphi, Amsterdam/Berlin, 2011.

[8] J. Porritt, "Green IT: The Global Benchmark", A report on sustainable IT in the USA, UK, Australia and India, Fujitsu, 2012.

[9] I. Ahmed, H. Okumura, and K. Arai, "An Informational Model as a Guideline to Design Sustainable Green SLA (GSLA)," International Journal of Advanced Computer Science and Applications, Vol.7, No.4, April 2016, pp. 302-310.

[10] Gartner Report (2015), Source: http://www.gartner.com/it-glossary/itservices.

[11] A. Chen, K. N. Dietrich, X. Huo, and S.-M. Ho, "Development Neurotoxicants in E-Waste: An Emerging Health Concern," Environmental Health Perspectives, Vol.119, No.4, April 2011.

[12] J. Jin, "Electromagnetic Analysis and Design in Magnetic Resonance Imaging," CRC Press, ISBN 978-0-8493-9693-9, September 1998.

[13] C. Tuppen, "Circularity and the ICT Sector," Advancing Sustainability LLP@ Ellen MacArthur Foundation, United Kingdom, September 2013.

[14] P. Sandborn, "Software Obsolescence- Complicating the Part and Technology Obsolescence Management Problem,” IEEE Transaction on Components and Packaging Technologies, Vol.30, No.4, December 2007, pp. 886-888.

[15] D. A. Levinthal, and D. Purohit, "Durable Goods and Product Obsolescence,” Marketing Science, Vol.8, No.1, printed in USA, Winter 1989.

[16] P. Singh, and P. Sandborn, "Obsolescence driven design refresh planning for sustainment-dominated systems," The Engineering Economist, Vol.51, No.2, June 2006, pp. 115-139.
[17] P. Mathew, S. Ganguly, S. Greenberg, and D. Sartor, "Self Benchmarking Guide for Data Centers: Metrics, Benchmarks, Actions," Report of New York State Energy Research \& Development Authority (NYSERDA), July 2009.

[18] T. Shiino, "Green IT by all Parties," PhD Presentation at Nomura Research Institute, Tokyo, Japan, March 2010.

[19] A. Atrey, N. Jain, and Iyengar N. Ch. S. N, “A Study on Green Cloud Computing," International Journal of Grid and Distributed Computing, Vol.6, No.6, 2013, pp. 93-102.

[20] E. Rondeau, F. Lepage, J. P. Georges, and G. Morel, "Measurements and Sustainability," Chapter 3, Green Information Technology, 1st Edition, A Sustainable Approach, Dastbaz \& Pattinson \& Akhgar, ISBN: 9780128013793, Elsevier Book, 304 pages, March 2015.

[21] F. Beister, M. Draxler, J. Aelken, and H. Karl, "Power model design for ICT systems - A generic approach," Computer Communication Journal, Vol. 50 (Special Issue), September 2014, pp. 77-85.

[22] T. R. Akinbinu, and Y. J. Mashalla, "Impact of Computer Technology on Health: Computer Vision Syndrome," Journal of Medical Practice and Review, Vol. 5 (3), November 2014, pp. 20-30.

[23] Anonymous, "The Effects of Computer Use on Eye Health and Vision," White Paper, American Optometric Association, 2014.

[24] P. Zhang, "Theorizing the Relationship between Affect and Aesthetics in ICT Design and Use Context," International Conference on Information Resource Management, Dubai, UAE, May 2009.

[25] Anonymous, "Emission factors for Greenhouse Gas Inventories," EPA (2014) Inventory of U.S Greenhouse Gas Emissions and Sinks, White Paper, April 2014.

[26] S. Naumann, M. Dick, E. Kern, and T. Johann, "The GREENSOFT Model: A reference model for green and sustainable software and its engineering," Sustainable Computing: Informatics and Systems Journal, Vol.1, No.4, June 2011, pp. 294-304.

[27] N. El-Sayed, I. Stefanovici, G. Amvrosiadis, Andy A. Hwang, and B. Schroeder, "Temparature Management in Data Centers: Why Some(Might) Like It Hot,” 2012 SIGMETRICS Conference, ACM Digital Library, London, UK, June 2012.

\section{Authors ProfiLe}

Kohei Arai, He received BS, MS and PhD degrees in 1972, 1974 and 1982, respectively. He was with The Institute for Industrial Science and Technology of the University of Tokyo from April 1974 to December 1978 also was with National Space Development Agency of Japan from January, 1979 to March, 1990. During from 1985 to 1987, he was with Canada Centre for Remote Sensing as a Post Doctoral Fellow of National Science and Engineering Research Council of Canada. He moved to Saga University as a Professor in Department of Information Science on April 1990. He was a councilor for the Aeronautics and Space related to the Technology Committee of the Ministry of Science and Technology during from 1998 to 2000 . He was a councilor of Saga University for 2002 and 2003. He also was an executive councilor for the Remote Sensing Society of Japan for 2003 to 2005. He is an Adjunct Professor of University of Arizona, USA since 1998. He also is Vice Chairman of the Commission "A" of ICSU/COSPAR since 2008. He wrote 33 books and published 510 journal papers. He is now Editor-in-Chief of IJACSA and IJISA. 